Pathologe 2009 • [Suppl 2] 30:251

DOI 10.1007/s00292-009-1176-6

Online publiziert: 2. Oktober 2009

(c) Springer Medizin Verlag 2009

\author{
H.H. Noeske \\ Buchholz i.d. Nordheide
}

\title{
Klaus Noeske
}

\subsubsection{4-31.03.2009}

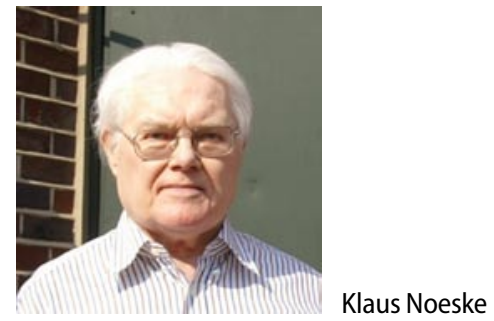

Am 31. März 2009 verstarb Prof. Dr. med. Klaus Noeske, ehemaliger Chefarzt des Pathologischen Instituts im Kreis Paderborn und Honorarprofessor der JustusLiebig-Universität Giessen.

Von 1953 bis 1959 studierte Klaus Noeske Humanmedizin an der Freien Universität Berlin, wo er im Februar 1959 das Staatsexamen ablegte. Ende Juni erfolgte bereits die Promotion. Seine Weiterbildungsstationen führten ihn über das Stadtkrankenhaus Rüsselsheim und das Pathologisch-Bakteriologische Institut des Stadtkrankenhauses Kassel zum Pathologischen Institut der Justus-LiebigUniversität in Giessen.

Dort wurde er unter Prof. Dr. med. Kracht zum Facharzt für Pathologie weitergebildet, gleichzeitig habilitierte er 1969 über „Die Zusammensetzung der Zellkernproteine und ihre Beziehung zum DNS-Gehalt im Verlauf der normalen Myelo- und Erythropoese beim Menschen".

Im Juli 1971 erfolgte die Ernennung zum Professor, sodann im August 1972 die Ernennung zum Kreisobermedizinalrat des Kreises Paderborn, verbunden mit dem Auftrag des Aufbaus und der Leitung eines Pathologischen Instituts, welches 1978 dem St. Johannisstift Paderborn angegliedert wurde.
Auch nach seiner Ernennung zum Leiter des Pathologischen Institutes des Kreises Paderborn stellte er als Honorarprofessor seine umfassenden fachlichen Kenntnisse in den Dienst der medizinischen Ausbildung, u. a. an der JustusLiebig-Universität Giessen.

Aus gesundheitlichen Gründen musste er sich 1992 aus seinem Wirkungskreis zurückziehen, gleichwohl blieb er seiner Arbeit durch gutachterliche Arbeiten einerseits und durch Besuche pathologischer Kongresse andererseits verbunden.

Wenige Tage vor seinem 75. Geburtstag schied Klaus Noeske nach einem Herzstillstand in den Morgenstunden des 31 . März 2009 friedlich dahin.

\section{Heinrich Noeske, Buchholz i.d. Nord- heide}

\section{Korrespondenzadresse}

\section{H.H. Noeske}

Buchholzer Landstr. 47 B

21244 Buchholz i.d. Nordheide 